\title{
Outcome Measures in Clubfoot
}

\author{
Soroush Baghdadi ${ }^{1}$, Prakash Yadav ${ }^{2}$, Bibek Banskota ${ }^{3}$, Alaric Aroojis ${ }^{4}$, Divya Talwar $^{5}$, David A Spiegel ${ }^{6}$
}

\begin{abstract}
The Ponseti method for the treatment of clubfoot is in widespread use around the globe, and while a variety of measures or tools have been used to evaluate outcomes, few have been validated in different contexts, and none have been standardized or universally accepted. Our goal is to review how outcomes are currently reported in the clubfoot literature, and we have chosen to frame the discussion based on a conceptual model, namely the World Health Organization's (WHO) International Classification of Functioning, Disability and Health (ICF). We have chosen to group outcome measures based on whether they are "impairment-based" or "function-based", the latter being subcategorized as healthcare provider-reported, patient/proxy-reported, or hybrid. Finally, we discuss the limitations of how clubfoot outcomes are currently reported, the challenges in accepting a universal outcome measure, and encourage the clubfoot researchers and clinicians to develop an outcome measure that can be used across cultures and throughout the developed and developing world, to homogenize clubfoot outcome measures and improve the standard-of-care.
\end{abstract}

Keywords: Clubfoot, Patient-reported outcome, Ponseti technique, Treatment outcome.

Journal of Foot and Ankle Surgery (Asia Pacific) (2021): 10.5005/jp-journals-10040-1188

\section{BACKGROUND}

The treatment of clubfoot has undergone a paradigm shift during the past several decades, with the minimally invasive Ponseti method becoming the standard of care and dramatically reducing the number of extensive surgical releases performed. Relative to feet treated by extensive surgery, those treated by the Ponseti method at long-term follow-up are more likely to be slightly undercorrected anatomically but with a better range of motion, strength, and function and less need for revision surgical procedures. ${ }^{1,2}$ The method may be delivered by non-surgeons (task shifting or sharing) which is of great benefit in environments where there are excessive demands on a limited surgical workforce. ${ }^{3}$

Despite extensive literature on clubfoot, there seems to be no standard or universally accepted means by which to evaluate the results of treatment. ${ }^{4}$ What is excellent, good, or fair, and according to whom? In the eyes of the examiner, clubfoot treatment "results" may be defined by static measurements such as range of motion, muscle strength, standing alignment of different segments of the foot, radiographic parameters on weight-bearing images, and/or findings on observational/instrumented gait analysis. In the eyes of the patient, the "results" may relate to whether and what shoes they can wear, whether they have pain or reduced endurance, how their feet look to others, and whether they are unable to participate in activities. In some settings, minor abnormalities in alignment or cosmetic concerns may be better tolerated as long as the function is normal, while in others the expectation may be that treatment will result in a normal foot.

We chose to frame this review of outcome measures used to evaluate clubfoot according to a conceptual framework developed at the World Health Organization (WHO), namely the International Classification of Functioning, Disability and Health (ICF)..$^{5}$ In this scheme, an "impairment" is defined as an abnormality in body structure or function (e.g., an equinovarus deformity of the foot), and the "disability" associated with that impairment is defined as a reduction in the ability to perform activities or to participate in life situations within a given contextual environment. There is no disability if an impairment is accommodated within a given
1,5,6 Department of Orthopaedic Surgery, Division of Orthopaedics, Children's Hospital of Philadelphia, Philadelphia, Pennsylvania, USA

${ }^{2,3} \mathrm{Hospital}$ and Rehabilitation Center for Disabled Children, Banepa, Nepal

${ }^{4}$ Department of Paediatric Orthopaedics, Bai Jerbai Wadia Hospital for Children, Acharya Donde Marg, Parel, Mumbai, Maharashtra, India

Corresponding Author: David A Spiegel, Department of Orthopaedic Surgery, Division of Orthopaedics, Children's Hospital of Philadelphia, Philadelphia, Pennsylvania, USA, Phone: +1 (215) 590-1527, e-mail: Spiegeld@chop.edu

How to cite this article: Baghdadi S, Yadav P, Banskota B, et al. Outcome Measures in Clubfoot. J Foot Ankle Surg (Asia Pacific) 2021;8(3): 132-140.

Source of support: Nil

Conflict of interest: None

environment, or if the patient can participate in all activities without a functional loss. We will group outcome measures for clubfoot into both "impairment" based, "function" based, or a combination of these, as evaluated by the provider, the patient, or a proxy for the patient. We will discuss the pros and cons of each measure and discuss the challenges in developing a universally accepted outcome measure that can be validated in different contexts.

\section{Impairment-based: Results According to the Healthcare Provider}

These measures would include static measurements on physical examination such as alignment, range of motion, strength, and assessment of ambulation, as well as radiographic parameters measured from weight-bearing images.

\section{Physical Examination}

The clinical appearance of the foot is the oldest outcome measure in clubfoot, which was initially reported by drawing the patient's feet in the journals. ${ }^{6}$ This was later supplanted by the clinician's perceived correction, thus reporting a "plantigrade 
foot" as a successful outcome. The ankle range of motion (ROM) is commonly reported, focusing on ankle dorsiflexion, which has a better correlation with the patient's function. However, ankle ROM measurements are rater-dependent and have low interrater reliability even when performed by a goniometer. ${ }^{7}$ Foot adduction, foot bimalleolar angle, pedobarograms, and an array of anthropometric measurements (calf circumference, foot width, height, and length) are other outcome measures reported in the literature. ${ }^{1,8,9}$

Evaluation of a virgin clubfoot is performed to determine the severity and predict the number of casts, the need for tenotomy, and the final outcome. There are several systems to grade the severity of clubfoot; the most familiar of those are that of Pirani, ${ }^{10}$ and Dimeglio. ${ }^{11}$ The Pirani score includes a hindfoot score and a midfoot score, each having three items graded as $0,0.5$, or 1 , with a total score of 0 to 6 . The Dimeglio classification scores four clinical parameters: equinus in the sagittal plane, varus in the coronal plane, rotation of the calcaneopedal block in the axial plane, and adduction of the forefoot relative to the hindfoot in the axial plane. Each item gets a score of 0 to 4 depending on severity. Four additional items add one score each if present and include: a posterior crease, a medial crease, cavus, muscular contractures. The total Dimeglio score ranges between 0 and 20 .

Both of these grading schemes show high inter-rater reliability and correlation with each other. ${ }^{12,13}$ The main purpose of developing these scoring systems has been to grade the severity of the clubfoot, to predict the number of casts, need for tenotomy, and risk of relapse. To this end, multiple studies have found their performance to be significant, reliable, and reproducible. ${ }^{14-16}$ However, their use for evaluating outcomes of treated clubfeet is neither validated nor intended. The clinical evaluation of a treated foot, especially in a walking child, might include static measurements of range of motion and alignment, evaluation of gait, presence of any symptoms and/or functional limitations, ability to participate in different activities, ability to wear different shoes, and the patient's general satisfaction. Interestingly enough, Dimeglio et al. introduced a classification system that incorporates functional evaluation, passive motion, muscle function, gait analysis, morphology, and radiographic analysis. ${ }^{17}$ Dimeglio et al. thus introduced two scoring systems at the same time, one for evaluation of the virgin clubfoot, and one for the final evaluation of the treated clubfoot.11,17 The former has been used extensively and has been cited close to 700 times (as of December 2020), and the latter $<80$ times, according to Google Scholar perhaps because the system is complex, has multiple domains, and utilizes radiographs. Preferably, non-physicians should also be able to score the physician domains. Both the original Dimeglio score and the Pirani score have been used in several clubfoot papers to report outcomes. ${ }^{18-20}$

\section{Imaging Studies}

Plain radiographs are an integral part of the evaluation of foot deformities, especially in older patients, and should be obtained in a weight-bearing position. Perhaps the most common radiographic measure is the anteroposterior talocalcaneal (TC) angle, or as colloquially known, the Kite angle; although Kite did not introduce the measure. ${ }^{21,22}$ Although the TC angle provides a rough measure of the hindfoot correction, it has been shown to have a poor correlation with computed tomography (CT) findings in up to $75 \%$ of cases. ${ }^{22}$ The TC angle on the anteroposterior and lateral views could be added to form the talocalcaneal index, for which numbers $>40$ are considered normal. ${ }^{23}$ Other common radiographic measures are talus-first metatarsal angle, tibial-calcaneal angle, tibiotalar angle, and the shape of the talar dome (flat-top talus). When a standard definition is used, all of these measurements have been shown to have a high inter- and intra-observer reliability. ${ }^{24}$

Ultrasonography is non-invasive, low-cost, can visualize the cartilaginous anlage of tarsal bones, and is therefore appropriate to evaluate the neonatal or infant foot for selected indications. This modality has been used to evaluate treated clubfoot including the healing of the tendoachilles after percutaneous release, ${ }^{25-27}$ and Desai et al. used ultrasound to evaluate feet during Ponseti treatment to evaluate the status of talonavicular reduction and the talo-cuneiform relationship. ${ }^{28}$ Using ultrasonography as an outcome measure is impractical in older patients.

Overall, while imaging studies are not obtained routinely during treatment with the Ponseti method, they may be quite useful in some older patients treated for the first time or especially in patients with residual deformities following treatment. Their value as an outcome measure is limited in that the measurements represent static relationships between segments of the foot and must be correlated with other physical findings and ideally with functional measures.

\section{Gait Analysis}

Observational and/or instrumented gait analysis evaluates foot alignment and positioning through the stance and swing phases of the gait cycle and complements findings on bench examination. Recognizing the challenges with marker placement around the foot and ankle for instrumented motion analysis, ${ }^{29}$ it is certainly important to be able to identify whether there is a drop foot or supination during the swing phase, as well as how the foot makes initial contact and is loaded during stance phase. Otis and Bohne were the first to report the results of instrumented gait analysis in treated clubfeet, ${ }^{30}$ and while they did not find the results to be significantly different between treated clubfeet and normal children, more recent studies have found a substantial correlation between the clinically assessed gait deviations and gait analysis results, as measured by gait profile score (GPS). ${ }^{31}$ Gait profile score is the root mean square difference between the patient's data and normal values for a set of kinematic variables and is mainly used in cerebral palsy research. ${ }^{32}$ Instrumented gait analysis is specifically helpful in determining the rotational profile of the limb while planning for derotational osteotomies. ${ }^{33}$ One very helpful component of a motion analysis study is pedobarography, which evaluates weight distribution at initial contact and through the stance phase. Although instrumented gait analysis is a powerful tool, it is time-consuming, expensive, and not readily available. Therefore, its applications are limited to special cases or the research setting. Furthermore, it does not consider the most important determinant of a good result: the patient's perspective.

\section{Pirani/Bohm/Sinclair}

The Pirani/Bohm/Sinclair (PBS) score is the most recent attempt at a simple and reliable tool to assess clubfoot outcomes. ${ }^{34}$ Pirani/ Bohm/Sinclair is a seven-item scoring system that also provides graphic examples for each answer for easier scoring. The first two items (hindfoot varus and supination) are assessed when the child is standing, the next two (swing phase supination and early heel rise) while walking, and the last three items (passive ankle dorsiflexion, active ankle dorsiflexion, and subtalar abduction) are evaluated 
when the child is sitting. The sum of all scores is calculated to a total score of between 7 and 18. This tool has been validated against the Roye score and has high reliability. ${ }^{34}$ No published studies have used this tool as an outcome measure so far.

\section{Function-based: Results According to the Patient and/ or their Proxy (PROM)}

Measurements of foot and ankle alignment/appearance, range of motion, strength, complemented by radiographic parameters, may or may not correlate with the ability to participate in activities and the perception of outcomes according to the patient and/or proxy. This has led to an interest in patient-reported outcome measures; however, the number of tools to assess the pediatric foot and ankle remains extremely limited.

\section{Oxford Ankle Foot Questionnaire for Children}

The Oxford Ankle Foot Questionnaire for Children (OxAFQ-C)is the only validated patient/proxy reported outcome measure for pediatric foot and ankle pathology, although it is not specifically designed for clubfoot. ${ }^{35}$ Development began with a qualitative study to identify foot and ankle issues from the child's perspective, and the tool includes 15 items including three domain scores including physical (6 items), emotional ( 4 items), and school and play (4 items), and a single question to assess whether the child can wear the footwear of their choice. Items are rated from 0 to 5 , and the final score is calculated as a percentage. This tool has been found to have high internal reliability when assessed by the patient and parents, and also high inter-rater reliability. ${ }^{36}$ The validity of this tool for use in children aged 5-16 years has been proven in subsequent studies. ${ }^{37}$ The minimal detectable changes (MDC) of 6-8 and minimally important difference (MID) of 7-17 were also established. ${ }^{36}$ Unlike other PROMs reviewed here, the OxAFQ-C has also been validated by independent researchers, including a Danish version, which was validated against the Child Health Questionnaire (CHQ) and showed high reliability, consistency, and feasibility. ${ }^{38}$ Although the OxAFQ-C tool has been extensively studied from a methodological standpoint and is a reliable, valid, and responsive outcome measure, only a few studies have used this tool as their outcome measure. . $^{2,39}$

\section{Patient-reported Outcomes Measurement Information System}

Patient-reported Outcomes Measurement Information System (PROMIS) was developed by the National Institute of Health (NIH) as a standardized PROM to use in all aspects of healthcare. ${ }^{40}$ Pediatric self- and proxy-reported versions have also been developed. Patient-reported Outcomes Measurement Information System is a general tool to evaluate health-related quality of life (QoL) and includes three components: physical health, mental health, and social health. There are several instruments for each component. Patient-reported Outcomes Measurement Information System has been used in a few clubfoot studies and has also been validated against disease-specific instrument (DSI). ${ }^{41,42}$ However, the correlation with DSI was only moderate, and PROMIS does not have an item for overall satisfaction. Furthermore, PROMIS has a substantial ceiling effect while evaluating clubfoot outcomes, meaning that it might not be able to measure improvements over time. $^{42}$ The use of PROMIS as a general health-related QoL outcome measure is encouraged. However, its use in reporting outcomes of clubfoot might lead to missing important surgeon-reported changes, overall patient/proxy satisfaction, and improvements over time (Table 1).

\section{Hybrid: Impairment- and Function-based \\ Laaveg-Ponseti}

Laaveg and Ponseti introduced the "functional rating system for clubfoot" in 1980, and this 100-point evaluation system is the sum of 70 patient-reported and 30 surgeon-reported points. ${ }^{43}$ Patients report their overall satisfaction (20 points), their function in daily activities (20 points), and pain (30 points). The surgeon adds the position of the heel while standing (10 points), passive motion (dorsiflexion, varus-valgus, and inversion-eversion, a total of 10 points), and gait (whether the patient can heel- and toe-walk, a total of 10 points). A score between 90 and 100 is considered excellent, 80-90 as good, $70-79$ as moderate, and below 70 as poor. The Laaveg-Ponseti score has yet to be validated.

Roye

Roye et al. introduced and validated a DSI for the assessment of clinical outcomes of clubfoot in $2001 .{ }^{44}$ The clubfoot DSI consists of 10 items to assess overall satisfaction, appearance, pain, and physical limitations. This was designed as a parent-reported measure, although in their follow-up study, the questionnaire was administered to patients. ${ }^{50}$ The score correlates well with general measures of children's health (PedsQL $\left.{ }^{\oplus} 4\right)$ and has a high internal consistency. ${ }^{51}$ Patients treated with Ponseti casting achieve a higher DSI score than patients who underwent posteromedial release or similar invasive procedures..$^{51}$ In a 16-year follow-up to their original study, Vitale et al. found that DSI correlates well with other measures of health-related QoL, although DSI measured foot-focused domains which general health measures lack. ${ }^{50}$ The main criticisms are that foot and ankle ROM and muscle strength are not included.

\section{Bangla Clubfoot Tool}

The Bangla tool incorporates static measurements as well as questions for parents extracted from the Roye questionnaire. ${ }^{44,45}$ This tool was specifically developed with low-resource settings in mind. The Bangla tool has 11 questions, each scored $-1,0$, or 1 , with a total score that ranges between -11 and +11 . Parents answer five questions: (1) Are you happy with your child's feet? (2) Would you recommend this program to others? (3) Does your child play with others? (4) Does your child wear shoes of choice? (5) Does your child have painful feet? Additionally, gait assessment by the provider receives four questions, including assessments of squatting, walking, running, and taking steps up and down. The varus/valgus position of the heel receives one score. Finally, ankle ROM is scored, with $>0^{\circ}$ receiving one point, no dorsiflexion zero points, and $<0^{\circ}$ dorsiflexion a score of -1 . This tool has high interrater reliability and has been used extensively in the setting of the Walk for Life program but has not been formally validated yet. ${ }^{45,52}$

\section{The International Clubfoot Study Group Score}

The International Clubfoot Study Group (ICFSG) classification system includes a comprehensive list of items. ${ }^{46}$ Morphology is evaluated in the hindfoot, midfoot, and the global alignment of the foot, and receives a maximum of 12 points. A functional evaluation includes an ankle ROM and muscular function, as well as gait and pain evaluation, with a total score of 36 . Standing AP and lateral radiographs are also evaluated and receive a total of 12 points. 
Table 1: Summary of the outcome measures in the current clubfoot literature

\begin{tabular}{|c|c|c|c|}
\hline Measure & Components & Scoring scale & $\begin{array}{l}\text { Validated and in what environ- } \\
\text { ment? }\end{array}$ \\
\hline \multicolumn{4}{|c|}{ Impairment-based: according to healthcare provider } \\
\hline \multirow[t]{3}{*}{ Pirani Score $(1999)^{10}$} & \multirow[t]{3}{*}{$\begin{array}{l}\text { Hindfoot score: } 3 \text { components } \\
\text { Midfoot score: } 3 \text { components }\end{array}$} & \multirow[t]{3}{*}{$\begin{array}{l}\text { Each item } 0,0.5,1 \\
\text { Total score } 0-6\end{array}$} & $\begin{array}{l}\text { Non-validated (either original or a } \\
\text { translation) }\end{array}$ \\
\hline & & & $\begin{array}{l}\text { Developed for virgin clubfoot in } \\
\text { infancy }\end{array}$ \\
\hline & & & $\begin{array}{l}\text { Not suitable as an outcome } \\
\text { measure }\end{array}$ \\
\hline \multirow[t]{5}{*}{ Dimeglio Score $(1995)^{11}$} & \multirow{2}{*}{$\begin{array}{l}\text { Four main items: } \\
\text { - Equinus } \\
\text { - Varus }\end{array}$} & \multirow[t]{5}{*}{$\begin{array}{l}\text { Each item 0-4 } \\
\text { Total score } 0-20\end{array}$} & $\begin{array}{l}\text { Non-validated (either original or a } \\
\text { translation) }\end{array}$ \\
\hline & & & $\begin{array}{l}\text { Intended for use in the virgin } \\
\text { clubfoot }\end{array}$ \\
\hline & $\begin{array}{l}\text { Rotation of the calcaneopedal } \\
\text { block }\end{array}$ & & $\begin{array}{l}\text { Not suitable as an outcome } \\
\text { measure, though the most }\end{array}$ \\
\hline & $\begin{array}{l}\text { - Forefoot adduction relative to } \\
\text { hindfoot }\end{array}$ & & $\begin{array}{l}\text { commonly reported outcome } \\
\text { measure in the literature }\end{array}$ \\
\hline & $\begin{array}{l}\text { Four bonus scores: posterior } \\
\text { crease, medial crease, cavus, } \\
\text { contractures }\end{array}$ & & \\
\hline \multirow{12}{*}{$\begin{array}{l}\text { Dimeglio/Bensahel Final } \\
\text { Evaluation of Clubfoot (1995) }\end{array}$} & \multirow{3}{*}{$\begin{array}{l}\text { Functional evaluation } \\
\text { - Passive motion (dorsi/plantar } \\
\text { flexion, subtalar motion, } \\
\text { supination/pronation) }\end{array}$} & \multirow{12}{*}{$\begin{array}{l}\text { The total score ranges from } \\
0 \text { to } 50\end{array}$} & Non-validated (either original or a \\
\hline & & & (Iransiation) \\
\hline & & & $\begin{array}{l}\text { Was developed to be com- } \\
\text { pared to the Dimeglio grading }\end{array}$ \\
\hline & \multirow{2}{*}{$\begin{array}{l}\text { - Muscle function (triceps, } \\
\text { flexors, dorsiflexors, peroneus) }\end{array}$} & & improvement \\
\hline & & & \multirow{8}{*}{$\begin{array}{l}\text { Hard to administer } \\
\text { Not used in the literature }\end{array}$} \\
\hline & - Function (walking, sports) & & \\
\hline & Morphology & & \\
\hline & $\begin{array}{l}\text { - Hindfoot (varus/valgus, } \\
\text { equinus) }\end{array}$ & & \\
\hline & $\begin{array}{l}\text { - Forefoot (supination, } \\
\text { adduction) }\end{array}$ & & \\
\hline & $\begin{array}{l}\text { - Global aspect (medial rotation, } \\
\text { pes cavus) }\end{array}$ & & \\
\hline & Radiographic & & \\
\hline & $\begin{array}{l}\text { - Eight measurements on AP and } \\
\text { lateral radiographs }\end{array}$ & & \\
\hline \multirow[t]{4}{*}{ Gait analysis } & - Pedobarography & \multirow[t]{4}{*}{ NA } & \multirow[t]{4}{*}{ Non-validated } \\
\hline & - Kinematics (joint angles) & & \\
\hline & - Kinetics (moments) & & \\
\hline & - Electromyography & & \\
\hline \multirow[t]{4}{*}{ Radiographic parameters } & - AP talocalcaneal angle & \multirow[t]{4}{*}{ NA } & Non-validated \\
\hline & - AP talo-first metatarsal angle & & High inter- and intraobserver \\
\hline & - Lateral talocalcaneal angle & & reliability \\
\hline & - Lateral tibiotalar angle & & Low correlation witn runction \\
\hline \multicolumn{4}{|c|}{ Function-based: According to the patient and/or proxy (PROM) } \\
\hline \multirow[t]{3}{*}{$\begin{array}{l}\text { Oxford Foot and Ankle } \\
\text { Questionnaire (OxFAQ) (2007) })^{37}\end{array}$} & \multirow{3}{*}{$\begin{array}{l}\text { A total of } 15 \text { items in } 3 \text { domains: } \\
\text { - Physical ( } 6 \text { items) }\end{array}$} & \multirow{3}{*}{$\begin{array}{l}\text { Items are rated from } 0 \text { to } 5 \text {, and } \\
\text { the final score is calculated as a } \\
\text { percentage }\end{array}$} & $\begin{array}{l}\text { The methodology is extensively } \\
\text { studied }\end{array}$ \\
\hline & & & Validated for use in clubfoot \\
\hline & & & High reliability, validity, feasibility \\
\hline
\end{tabular}


Contd...

\begin{tabular}{|c|c|c|c|}
\hline Measure & Components & \multirow[t]{3}{*}{ Scoring scale } & $\begin{array}{l}\text { Validated and in what environ- } \\
\text { ment? }\end{array}$ \\
\hline \multirow{6}{*}{$\begin{array}{l}\text { Patient-Reported Outcomes } \\
\text { Measurement Information System } \\
\text { (PROMIS) }(2004)^{40}\end{array}$} & \multirow[t]{2}{*}{$\begin{array}{l}\text { School and play ( } 4 \text { items) } \\
\text { A single question to assess } \\
\text { whether the child can wear the } \\
\text { footwear of their choice. }\end{array}$} & & $\begin{array}{l}\text { Several translations are validated } \\
\text { and available (Danish, Farsi, Ger- } \\
\text { man, Italian, Korean, and French, } \\
\text { among others) }\end{array}$ \\
\hline & & & $\begin{array}{l}\text { Validated in the low-resource } \\
\text { setting in developing countries }\end{array}$ \\
\hline & \multirow{4}{*}{$\begin{array}{l}\text { Three main components: } \\
\text { - Physical health } \\
\text { - Mental health } \\
\text { - Social health }\end{array}$} & \multirow{4}{*}{$\begin{array}{l}\text { Raw scores are converted to a } \\
\text { T-score, scaled to a mean of } 50 \\
\text { and SD of } 10\end{array}$} & $\begin{array}{l}\text { Validated for use in children as a } \\
\text { general HR-QoL measure }\end{array}$ \\
\hline & & & Validated in clubfoot, although \\
\hline & & & $\begin{array}{l}\text { only in developed countries, and } \\
\text { only the English version }\end{array}$ \\
\hline & & & $\begin{array}{l}\text { Considerable ceiling effect: not } \\
\text { able to measure improvement } \\
\text { over time }\end{array}$ \\
\hline \multicolumn{4}{|c|}{ Hybrid: Impairment and function-based } \\
\hline Laaveg-Ponseti $(1980)^{43}$ & $\begin{array}{l}\text { Patient-reported: } \\
\text { - } \text { Overall satisfaction ( } 20 \text { points) } \\
\text { - } \text { Function in daily activities ( } 20 \\
\text { points) } \\
\text { - Pain ( } 30 \text { points) } \\
\text { Surgeon-reported: } \\
\text { - Heel position when standing } \\
\text { (10 points) } \\
\text { - Passive motion (dorsiflexion, } \\
\text { varus-valgus, and inversion- } \\
\text { eversion, a total of } 10 \text { points) } \\
\text { - Gait (whether the patient can } \\
\text { heel- and toe-walk, a total of } \\
10 \text { points) }\end{array}$ & $\begin{array}{l}\text { A total score of } 100 \text {, with } 70 \\
\text { patient-reported and } 30 \text { surgeon- } \\
\text { reported points. A score }>90 \text { is } \\
\text { considered excellent }\end{array}$ & $\begin{array}{l}\text { Non-validated (either original or a } \\
\text { translation) }\end{array}$ \\
\hline \multirow[t]{2}{*}{ Roye $(2001)^{44}$} & $\begin{array}{l}10 \text { items to assess the outcomes } \\
\text { pertaining to overall satisfaction, } \\
\text { appearance, pain, and physical } \\
\text { limitations }\end{array}$ & & $\begin{array}{l}\text { Validated only in developed } \\
\text { countries (A validated Dutch ver- } \\
\text { sion is also available in addition } \\
\text { to the original English) }\end{array}$ \\
\hline & & & $\begin{array}{l}\text { Correlates well with general HR- } \\
\text { QoL measures }\end{array}$ \\
\hline \multirow[t]{10}{*}{ The Bangla Clubfoot Tool $(2014)^{45}$} & $\begin{array}{l}\text { Parent/proxy-reported (five } \\
\text { items): }\end{array}$ & -11 to +11 & $\begin{array}{l}\text { Developed and validated in } \\
\text { low-resource settings (English } \\
\text { version) }\end{array}$ \\
\hline & - Happy with child's feet? & & $\begin{array}{l}\text { High inter- and intraobserver } \\
\text { reliability }\end{array}$ \\
\hline & - Recommend to others? & & Based on the Roye questionnaire \\
\hline & - Child plays with others? & & \\
\hline & $\begin{array}{l}\text { Wears shoes of your/their } \\
\text { choice? }\end{array}$ & & \\
\hline & - Painful feet? & & \\
\hline & Provider-reported: & & \\
\hline & $\begin{array}{l}\text { - Gait (four items): squatting, } \\
\text { walking, running, steps }\end{array}$ & & \\
\hline & $\begin{array}{l}\text { - Heel position (one item): varus/ } \\
\text { valgus }\end{array}$ & & \\
\hline & - Ankle ROM (one item) & & \\
\hline
\end{tabular}


Contd...

\begin{tabular}{|c|c|c|c|}
\hline Measure & Components & Scoring scale & $\begin{array}{l}\text { Validated and in what environ- } \\
\text { ment? }\end{array}$ \\
\hline \multirow[t]{4}{*}{$\begin{array}{l}\text { The International Clubfoot Study } \\
\text { Group (ICFSG) score }(2003)^{46}\end{array}$} & $\begin{array}{l}\text { A comprehensive list of items } \\
\text { assessing: }\end{array}$ & \multirow[t]{4}{*}{ Total score of $0-60$} & $\begin{array}{l}\text { Non-validated (either original or a } \\
\text { translation) }\end{array}$ \\
\hline & & & $\begin{array}{l}\text { Relatively low interobserver } \\
\text { agreement }\end{array}$ \\
\hline & - Radiology & & \multirow{2}{*}{$\begin{array}{l}\text { Rarely used except by the } \\
\text { developing team }\end{array}$} \\
\hline & - Function & & \\
\hline \multirow[t]{4}{*}{$\begin{array}{l}\text { Pirani/Bohm/Sinclair (PBS) } \\
(2019)^{34}\end{array}$} & \multirow[t]{2}{*}{$\begin{array}{l}\text { Seven item scoring system: } \\
\text { - Child standing (hindfoot } \\
\text { varus and supination) }\end{array}$} & \multirow[t]{4}{*}{ Total score 7-18 } & \multirow{4}{*}{$\begin{array}{l}\text { Validated against Roye score, } \\
\text { only in developed countries (No } \\
\text { translation available) } \\
\text { High reliability } \\
\text { Has not been used in clubfoot } \\
\text { studies yet }\end{array}$} \\
\hline & & & \\
\hline & \multirow{2}{*}{$\begin{array}{l}\text { Child walking (swing phase } \\
\text { supination and early } \\
\text { heel rise) } \\
\text { - Child sitting (passive and } \\
\text { active ankle dorsiflexion, and } \\
\text { subtalar abduction) }\end{array}$} & & \\
\hline & & & \\
\hline \multirow[t]{12}{*}{ Ezra score $(2000)^{47}$} & \multirow{4}{*}{$\begin{array}{l}\text { - Ankle dorsiflexion } \\
\text { - Subtalar motion } \\
\text { - Heel position }\end{array}$} & \multirow[t]{12}{*}{ Total score of 150} & \multirow{4}{*}{$\begin{array}{l}\text { Non-validated in any setting } \\
\text { (either original or a translation) } \\
\text { Interobserver agreement not } \\
\text { assessed } \\
\text { Rarely used }\end{array}$} \\
\hline & & & \\
\hline & & & \\
\hline & & & \\
\hline & \multirow{8}{*}{$\begin{array}{l}\text { - } \text { Supination } \\
\text { - } \text { Cavus } \\
\text { - Gait } \\
\text { - Shoe type } \\
\text { - } \text { Functional limitations } \\
\text { - Pain } \\
\text { - Patient satisfaction } \\
\text { - TA tendon function }\end{array}$} & & \\
\hline & & & \\
\hline & & & \\
\hline & & & \\
\hline & & & \\
\hline & & & \\
\hline & & & \\
\hline & & & \\
\hline \multirow{5}{*}{$\begin{array}{l}\text { The Institution of Motion Analysis } \\
\text { and Research (IMAR) Clubfoot } \\
\text { Scale }(2009)^{48}\end{array}$} & \multirow{2}{*}{$\begin{array}{l}\text { Three sections: } \\
\text { - Questionnaire (symptoms, } \\
\text { function) }\end{array}$} & \multirow{5}{*}{$\begin{array}{l}\text { Scores are deducted for each } \\
\text { abnormality from an initial score } \\
\text { of } 100\end{array}$} & Non-validated (either original or a \\
\hline & & & translatıon) \\
\hline & \multirow{2}{*}{$\begin{array}{l}\text { - Examination (appearance of } \\
\text { the foot) }\end{array}$} & & $\begin{array}{l}\text { Not a high reliability (inter-rater } \\
0.79 \text { ) }\end{array}$ \\
\hline & & & Too complex for routine use \\
\hline & $\begin{array}{l}\text { - Gait data (static and } \\
\text { dynamic pedobarography, } \\
\text { temporospatial data) }\end{array}$ & & $\begin{array}{l}\text { Utilizes gait data which is } \\
\text { impractical in most settings }\end{array}$ \\
\hline \multirow[t]{4}{*}{$\begin{array}{l}\text { Assessing Clubfoot Treatment } \\
\text { Tool (ACT) }(2017)^{49}\end{array}$} & \multirow{2}{*}{$\begin{array}{l}\text { Three questions: } \\
\text { - Does your child complain of } \\
\text { pain in their affected foot? }\end{array}$} & \multirow{4}{*}{ Scores $0-3$} & Validated in low-resource settings \\
\hline & & & $\begin{array}{l}\text { Sensitive and specific in } \\
\text { diagnosing patients who would } \\
\text { require additional treatment }\end{array}$ \\
\hline & $\begin{array}{l}\text { - Can your child wear shoes of } \\
\text { your/their choice? and }\end{array}$ & & $\begin{array}{l}\text { Cannot be used to quantify and } \\
\text { compare outcomes }\end{array}$ \\
\hline & $\begin{array}{l}\text { - How satisfied are you with your } \\
\text { child's foot? }\end{array}$ & & \\
\hline
\end{tabular}


This system has a total score of $0-60$; scores of $0-5$ are considered excellent, $6-15$ good, $16-30$ fair, and $>30$ poor results. The intra- and interobserver agreement of ICFSG is only 0.62 and 0.73 , respectively, which is lower than those of other clubfoot outcomes measures. ${ }^{53}$ Outside of the studies by the group that developed the tool, it has rarely been used to report outcomes.

\section{Ezra Score}

This functional scoring system was developed and introduced in a study by Ezra et al. while reporting the results of tibialis anterior tendon transfers in clubfoot. ${ }^{47}$ It incorporates clinical findings (ankle ROM, subtalar motion, heel position, forefoot appearance, and supination), functional assessment (gait, shoe type, functional limitations, pain), and patient satisfaction with a total score of up to 150 . This system has rarely been used, is not validated, and its interobserver reliability has not been assessed.

\section{Institution of Motion Analysis and Research}

The Institution of Motion Analysis and Research (IMAR) clubfoot scale was developed in the United Kingdom. ${ }^{48}$ The IMAR scale combines clinical and biomechanical data to assess function and predict the need for further treatment. Symptoms, function, and whether or not the child can keep up with peers form the questionnaire section of the scale, while anthropometric measurements are used to evaluate the appearance. Static and dynamic pedobarography data, as well as temporospatial data, are used to score the biomechanical aspect of the foot. Scores are deducted for each abnormality from an initial score of 100 , and a score of $>70$ is considered excellent. Due to the difficulties of collecting the data and the proprietary nature of some of the devices used, this tool has only been used a few times, and only by the developing group.

\section{Assessing Clubfoot Treatment Tool}

The Assessing Clubfoot Treatment Tool (ACT) was developed in 2017 using a Delphi method and consists of one question about the plantigrade position of the foot, answered by the practitioner, and three questions answered by the parents: (1) Does your child complain of pain in their affected foot? (2) Can your child wear shoes of your/their choice? and (3) How satisfied are you with your child's foot $?^{49}$ The tool has been validated by the same group. ${ }^{54}$ While ACT is sensitive and specific in diagnosing patients who would require additional treatment for their clubfoot, it does not provide quantitative information about the outcome except that the foot needs further treatment.

\section{Conclusion}

Though the Ponseti method has been established as the standard of care for the treatment of clubfoot with excellent short- and long-term results, there remains no well-accepted tool or outcome measure which can evaluate the success of treatment and compare studies in the literature. Do we listen to the health provider, the patient/their proxy, or both? Do we focus on static measurements such as alignment, range of motion, appearance, a dynamic measure such as gait analysis with pedobarography, functional measures according to the patient or a proxy, or a combination of these? Recognizing that adequate patient satisfaction is the ultimate goal, the ability to accurately characterize the structural residua following treatment should certainly be helpful if they can be correlated with function. Therefore, it would seem that a composite measure would be desirable, one that defines restoration of structure and also determines how the patient functions in life, perhaps as separate modules. It is also critical that a tool or outcome measure be translated into local languages and be validated within the context where it will be administered. While validating translated instruments will be cumbersome and time-consuming, it is essential for the cross-cultural use of PROMs, especially in the setting of clubfoot, in which there is a strong cultural underlying to the patient/parent-reported outcomes. A foot that is considered normal by the patient, parents, and the community at large in an affluent city in an economically developed environment may not be the same in a rural area in an economically underdeveloped region. For example, squatting is an indispensable function of daily life in certain parts of the world, in cultures where a majority of activities are performed close to the floor, and a loss of dorsiflexion may impact function. Furthermore, in areas in which one has to walk on steeply inclined roads for long periods of time, loss of ankle dorsiflexion might also be associated with substantial disability, while it may be nearly unnoticeable if the patient mostly walks on flat surfaces. Ideally, researchers would strive to develop by consensus, an outcome tool based on pre-selected core outcome sets, which can then be translated and validated in different contexts, so that outcomes may be compared both within and between different centers. The tool should ideally evaluate correction of structural abnormalities (impairment) and also evaluate the level of function (disability) according to the patient ideally, or their proxy. This could be achieved through a multidisciplinary working group, including health providers from both economically developed and underdeveloped regions, social scientists, and experts in the design and testing of outcome measures.

\section{References}

1. Abbas M, Qureshi OA, Jeelani LZ, et al. Management of congenital talipes equinovarus by Ponseti technique: a clinical study. J Foot Ankle Surg 2008;47(6):541-545. DOI: 10.1053/j.jfas.2008.07.002.

2. Duffy CM, Salazar JJ, Humphreys L, et al. Surgical versus Ponseti approach for the management of CTEV: a comparative study. J Pediat Orthop 2013;33(3):326-332. DOI: 10.1097/BPO.0b013e31827d0b2c.

3. Spiegel DA, Shrestha OP, Sitoula P, et al. Ponseti method for untreated idiopathic clubfeet in Nepalese patients from 1 to 6 years of age. Clin Orthop Relat Res 2009;467(5):1164-1170. DOI: 10.1007/s11999-0080600-1.

4. Gelfer Y, Hughes KP, Fontalis A, et al. A systematic review of reported outcomes following Ponseti correction of idiopathic club foot. Bone Joint Open 2020;1(8):457-464. DOI: 10.1302/2633-1462.18.BJO-20200109.R1.

5. Stucki G, Cieza A, Ewert T, et al. Application of the international classification of functioning, disability and health (ICF) in clinical practice. Disabil Rehabilit 2002;24(5):281-282. DOI: 10.1080/09638280110105222.

6. Little WJ. A treatise on the nature of club-foot, and analogous distortions; including their treatment both with and without surgical operation. Med Chir Rev 1840;32(64):423-445.

7. Martin RL, McPoil TG. Reliability of ankle goniometric measurements: a literature review. J Am Podiat Med Associat 2005;95(6):564-572. DOI: $10.7547 / 0950564$.

8. Chesney D, Barker S, Maffulli N. Subjective and objective outcome in congenital clubfoot; a comparative study of 204 children. BMC Musculoskelet Disord 2007;8(1):53. DOI: 10.1186/1471-2474-8-53.

9. Agarwal A, Rastogi A. Anthropometric measurements in Ponseti treated clubfeet. SICOT J 2018;4:19. DOI: 10.1051/sicotj/2018010.

10. Pirani S, Outerbridge HK, Sawatzky B, et al. A reliable method of clinically evaluating a virgin clubfoot evaluation. Vol. 29. In 21st SICOT Congress; 1999. pp. 2-30. 
11. Dimeglio $A$, Bensahel $H$, Souchet $P$, et al. Classification of clubfoot. J Pediat Orthop B 1995;4(2):129-136. DOI: 10.1097/01202412199504020-00002.

12. Shaheen S, Jaiballa H, Pirani S. Interobserver reliability in Pirani clubfoot severity scoring between a paediatric orthopaedic surgeon and a physiotherapy assistant. J Pediat Orthop B 2012;21(4):366-368. DOI: 10.1097/BPB.0b013e3283514183.

13. Fan $H$, Liu $Y$, Zhao $L$, et al. The correlation of pirani and dimeglio scoring systems for Ponseti management at different levels of deformity severity. Scienti Rep 2017;7(1):1-8.

14. Agarwal A, Gupta N. Does initial Pirani score and age influence number of Ponseti casts in children? Int Orthop 2014;38(3):569-572. DOI: 10.1007/s00264-013-2155-3.

15. Asuquo J, Anisi C, Abang I, et al. The predictive value of the pirani scoring system. J Pediat Orthop Part B 2019;28(3):296.

16. Gao R, Tomlinson M, Walker C. Correlation of Pirani and Dimeglio scores with number of Ponseti casts required for clubfoot correction. J Pediatr Orthop 2014;34(6):639-642. DOI: 10.1097/ BPO.0000000000000182.

17. Bensahel H, Dimeglio A, Souchet P. Final evaluation of clubfoot. J Pediat Orthop Part B 1995;4(2):137-141. DOI: 10.1097/01202412199504020-00003.

18. Agarwal A, Gupta S, Sud A, et al. Results of modified Ponseti technique in difficult clubfoot and a review of literature. J Clin Orthop Trauma 2020;11(2):222-231. DOI: 10.1016/j.jcot.2019.05.003.

19. Ahmad AA, Aker L. Accelerated Ponseti method: first experiences in a more convenient technique for patients with severe idiopathic club feet. Foot Ankle Surg 2020;26(3):254-257. DOI: 10.1016/j. fas.2019.03.003.

20. Altaf KA, Shah SBS, Ahmad S, et al. Results of JESS (Joshi's external stabilizing system) in relapsed, neglected and neurogenic clubfoot in an age group of 2-10 years. Ortop Traumatol Rehabil 2020;22(2):121129. DOI: 10.5604/01.3001.0014.1170.

21. Kite JH. Conservative treatment of the resistant recurrent clubfoot. Clin Orthop Relat Res 1970;70(70):93-110. DOI: 10.1097/00003086197005000-00011.

22. Ippolito E, Fraracci L, Farsetti P, et al. Validity of the anteroposterior talocalcaneal angle to assess congenital clubfoot correction. Am J Roentgenol 2004;182(5):1279-1282. DOI: 10.2214/ajr.182.5.1821279.

23. DePuy J, Drennan JC. Correction of idiopathic clubfoot: a comparison of results of early versus delayed posteromedial release. J Pediatr Orthop 1989;9(1):44-48. DOI: 10.1097/01241398-198901000-00009.

24. Davids JR, Gibson TW, Pugh LI. Quantitative segmental analysis of weight-bearing radiographs of the foot and ankle for children: normal alignment. J Pediat Orthop 2005;25(6):769-776. DOI: 10.1097/01. bpo.0000173244.74065.e4.

25. Barker SL, Lavy CBD. Correlation of clinical and ultrasonographic findings after Achilles tenotomy in idiopathic club foot. J of Bone Joint Surg Ser B 2006;88(3):377-379. DOI: 10.1302/0301-620X.88B3.17273.

26. Nasr P, Berman L, Rehm A. Ultrasonographic findings after Achilles tenotomy during Ponseti treatment for clubfeet: is ultrasound a reliable tool to assess tendon healing? J Child Orthop 2014;8(5):405411. DOI: 10.1007/s11832-014-0610-3.

27. Watzl MTP, Dos Santos A, Ferreira Neto AL, et al. Ultrasonographic aspects of the Achilles tendon after tenotomy for the treatment of congenital clubfoot by the Ponseti technique. Radiol Bras 2020;53(1):34-35. DOI: 10.1590/0100-3984.2018.0086.

28. Desai S, Aroojis A, Mehta R. Ultrasound evaluation of clubfoot correction during Ponseti treatment: a preliminary report. J Pediatr Orthop 2008;28(1):53-59. DOI: 10.1097/bpo.0b013e31815a60a6.

29. Di Marco R, Rossi S, Racic V, et al. Concurrent repeatability and reproducibility analyses of four marker placement protocols for the foot-ankle complex. J Biomechan 2016;49(14):3168-3176. DOI: 10.1016/j.jbiomech.2016.07.041.

30. Otis JC, Bohne WHO. Gait analysis in surgically treated clubfoot. J Pediat Orthop 1986;6(2):162-164. DOI: 10.1097/01241398-19860300000008.
31. Akşahin E, Yüksel HY, Yavuzer G, et al. Quantitative gait characteristics of children who had successful unilateral clubfoot operation. Acta Orthop Traumatol Turc 2010;44(5):378-384. DOI: 10.3944/ AOTT.2010.2352.

32. Baker R, McGinley JL, Schwartz MH, et al. The gait profile score and movement analysis profile. Gait Posture 2009;30(3):265-269. DOI: 10.1016/j.gaitpost.2009.05.020.

33. Sankar WN, Rethlefsen SA, Weiss J, et al. The recurrent clubfoot: can gait analysis help us make better preoperative decisions? Clin Orthop Relat Res 2009;467(5):1214-1222. DOI: 10.1007/s11999-008-0665-x.

34. Böhm S, Sinclair M. The PBS Score-a clinical assessment tool for the ambulatory and recurrent clubfoot. J Children's Orthop 2019;13(3):282-292. DOI: 10.1302/1863-2548.13.190077.

35. Morris C, Liabo K, Wright P, et al. Development of the Oxford ankle foot questionnaire: finding out how children are affected by foot and ankle problems. Child: Care, Health Develop 2007;33(5):559-568. DOI: 10.1111/j.1365-2214.2007.00770.x.

36. Morris C, Doll H, Davies N, et al. The oxford ankle foot questionnaire for children: responsiveness and longitudinal validity. Qual Life Res 2009;18(10):1367. DOI: 10.1007/s11136-009-9550-7.

37. Morris C, Doll H, Wainwright A, et al. The Oxford ankle foot questionnaire for children: scaling, reliability and validity. J Bone Joint Surg Br Vol 2008;90(11):1451-1456. DOI: 10.1302/0301620X.90B11.21000.

38. Martinkevich P, Møller-Madsen B, Gottliebsen M, et al. Validation of the translated Oxford ankle foot questionnaire in 82 Danish children aged between five and 16 years. Bone Joint J 2015;97(3):420-426.

39. Banskota B, Yadav P, Rajbhandari T, et al. Outcomes of the Ponseti method for untreated clubfeet in Nepalese patients seen between the ages of one and five years and followed for at least 10 years. J Bone Joint Surg Am 2018;100(23):2004-2014. DOI: 10.2106/JBJS.18.00445.

40. Bevans M, Ross A, Cella D. Patient-reported outcomes measurement information system (PROMIS): efficient, standardized tools to measure self-reported health and quality of life. Nurs Outlook 2014;62(5):339-345. DOI: 10.1016/j.outlook.2014.05.009.

41. Khan AA, Abarca N, Cung NQ, et al. Use of PROMIS in assessment of children with Ponseti-treated idiopathic clubfoot: better scores with greater than 3 years of brace use. J Pediat Orthop 2020;40(9):526-530. DOI: $10.1097 / B P O .0000000000001556$.

42. Masrouha KZ, Moses MJ, Sala DA, et al. The validity of patientreported outcome measurement information system (PROMIS) parent proxy instruments to assess function in children with talipes equinovarus. J Pediat Orthop 2019;39(10):e787-e790. DOI: 10.1097/ BPO.0000000000001368.

43. Laaveg SJ.Ponseti IV. Long-term results of treatment of congenital club foot. J Bone Joint Surg Am 1980;62(1):23-31. DOI: 10.2106/00004623198062010-00004.

44. Roye BD, Vitale MG, Gelijns AC, et al. Patient-based outcomes after clubfoot surgery. J Pediat Orthop 2001;21(1):42-49. DOI: 10.1097/01241398-200101000-00010.

45. Evans AM, Perveen R, Ford-Powell VA, et al. The Bangla clubfoot tool: a repeatability study. J Foot Ankle Res 2014;7(1):27. DOI: 10.1186/17571146-7-27.

46. Bensahel $\mathrm{H}, \mathrm{KuoK}$, Duhaime M. Outcome evaluation of the treatment of clubfoot: The international language of clubfoot. J Pediat Orthop Part B 2003;12(4):269-271. DOI: 10.1097/01202412-200307000-00006.

47. Ezra E, Hayek S, Gilai AN, et al. Tibialis anterior tendon transfer for residual dynamic supination deformity in treated club feet. J Pediat Orthop Part B 2000;9(3):207-211. DOI: 10.1097/01202412-20000600000012.

48. Ramanathan A, Herd F, Macnicol M, et al. A new scoring system for the evaluation of clubfoot: the IMAR-Clubfoot scale. The Foot 2009;19(3):156-160. DOI: 10.1016/j.foot.2009.04.001.

49. Smythe T, Wainwright A, Foster A, et al. What is a good result after clubfoot treatment? a delphi-based consensus on success by regional clubfoot trainers from across Africa. PLoS ONE 2017;12(12):e0190056. DOI: 10.1371/journal.pone.0190056. 
50. Vitale MG, Choe JC, Vitale MA, et al. Patient-based outcomes following clubfoot surgery: a 16-year follow-up study. J Pediat Orthop 2005;25(4):533-538. DOI: 10.1097/01.bpo.0000157999.38424.ba.

51. Dietz FR, Tyler MC, Leary KS, et al. Evaluation of a disease-specific instrument for idiopathic clubfoot outcome. Clin Orthop Relat Res 2009;467(5):1256-1262. DOI: 10.1007/s11999-008-0700-y.

52. Perveen R,Evans AM,Ford-PowellV, etal.TheBangladesh clubfoot project: audit of 2-year outcomes of Ponseti treatment in 400 children. J Pediat Orthop 2014;34(7):720-725. DOI: 10.1097/BPO.0000000000000225.
53. Celebi L, Muratli HH, Aksahin E, et al. Bensahel et al. and International Clubfoot Study Group evaluation of treated clubfoot: assessment of interobserver and intraobserver reliability. J Pediat Orthop B 2006;15(1):34-36. DOI: 10.1097/01202412-20060100000007.

54. Smythe T, Mudariki D, Gova M, et al. Evaluation of a simple tool to assess the results of Ponseti treatment for use by clubfoot therapists: a diagnostic accuracy study. J Foot Ankle Res 2019;12(1):14. DOI: 10.1186/ s13047-019-0323-4. 